\title{
Parental Problem-drinking and Adult Children's Labor Market Outcomes
}

\begin{abstract}
Ana I. Balsa
A B S T R A C T

Current estimates of the societal costs of alcoholism do not consider the impact of parental drinking on children. This paper analyzes the consequences of parental problem-drinking on children's labor market outcomes in adulthood. Using the NLSY79, I show that having a problemdrinking parent is associated with longer periods out of the labor force, lengthier unemployment, and lower wages, in particular for male respondents. Increased probabilities of experiencing health problems and abusing alcohol are speculative forces behind these effects. While causality cannot be determined due to imprecise IV estimates, the paper calls for further investigation of the intergeneration costs of problem-drinking.
\end{abstract}

\section{Introduction}

An important avenue of research in economics involves the identification and measurement of the economic costs of alcoholism. In most cases, the scope of this research has been limited to studying the consequences directly associated with the problem-drinking subject: for example, productivity losses, health care costs, and other costs directly resulting from the criminal activities of the subject. Less is known, however, about indirect economic costs of alcoholism such as, for instance, the costs that one family member's drinking inflicts upon other family members.

Ana I. Balsa is a visiting scientist with the Health Economics Research Group (HERG) at the University of Miami and a visiting professor at the University of Montevideo, Uruguay. Financial assistance for this study was provided by the National Institute on Alcohol Abuse and Alcoholism (grant number R01 AA13167). The author gratefully acknowledges comments and suggestions by attendants to the HERG research meetings, three anonymous referees, William Russell for editorial assistance, and Jamila Wade and Colleen Trifilo for research assistance. The results, opinions, and positions presented in this paper reflect the views of the author alone and do not necessarily represent those of the University of Miami or the National Institute on Alcohol Abuse and Alcoholism. The data used in this article can be obtained beginning October 2008 through September 2011 from Ana I. Balsa, Ph.D., University of Miami, Sociology Research Center, 5665 Ponce de Leon Boulevard, Flipse Building room 122, Coral Gables, FL 33146-0719, U.S.A.; abalsa@miami.edu.

[Submitted January 2006; accepted June 2007]

ISSN 022-166X E-ISSN 1548-8004 (C) 2008 by the Board of Regents of the University of Wisconsin System

THE JOURNAL OF HUMAN RESOURCES • XLIII • 2 
This paper takes advantage of the 1979 cohort of the National Longitudinal Survey of Youth (NLSY79), a rich, nationally representative longitudinal data set, to analyze the economic effects of parental problem-drinking on children. Specifically, the paper focuses upon labor market outcomes of adult children of alcoholics, including labor force participation, unemployment, and wages. Results are suggestive of intergeneration costs of problem-drinking, but the analysis cannot reach definite conclusions about the causality of the effects.

Alerting the public to the consequences of parental drinking has significant implications for public policy. In general, the costs that children of alcoholics have to bear because of parental alcoholism are not considered when evaluating the economic consequences of alcohol abuse, nor are they taken into account when designing relevant interventions. The current paper sheds new light on the economical significance of parental problem-drinking and emphasizes the importance of considering these costs when designing, evaluating, and funding interventions.

Section II surveys the previous literature on the effects of parental alcoholism in children and provides some insight on the pathways through which alcohol misuse by a parent could affect a child's labor market outcomes at adulthood. A description of the NLSY79 data, the variables used in the analysis, and the estimation methods is provided in Section III. Section IV reports the results and checks for robustness using alternate methodologies. In Section V, results are discussed and a conclusion is offered.

\section{Background and Significance}

Most of the previous research on children of alcoholics has been performed in the fields of clinical psychology and family medicine. Findings suggest that children of alcoholics are at higher risk than other children for depression, anxiety disorders, problems with cognitive and verbal skills, and parental abuse or neglect during childhood (NIAAA 2000). The bulk of the research focuses on the short- to medium-term sequels that parental alcohol misuse has on children. Although many studies relate parental alcoholism to higher likelihood of children engaging in problematic drinking, it remains unclear whether parental problemdrinking leaves a long-term economic imprint on children.

Connell and Goodman (2002) identify four mechanisms that relate parental alcohol abuse to children's adverse outcomes: (1) genetics; (2) complications during prenatal development; (3) exposure to the parent's behavior and knowledge; and (4) environmental stressors such as economic pressure, marital conflict, and disruption that are more common in a home with an alcoholic or problem-drinking parent. By affecting mental and physical health, levels of IQ, learning capabilities, substance use patterns, and attitudes in general, each of these mechanisms can shape a child's future labor market success.

The higher propensity of children of alcoholics to develop drinking problems is a first pathway that could relate parental drinking to children's labor market outcomes at adulthood. A family history of alcoholism has been identified as a critical predisposing factor of high risk for alcohol dependence at later ages (Jennison and Johnson 1998; Windle 1996; Jennison and Johnson 2001). Findings of twin and adoption 
studies have enhanced the understanding of genetic susceptibility to alcohol dependence (McGue 1997). Prevalence of alcoholism among first-degree relatives of individuals suffering from alcoholism is 3-4 times greater than it is among the general population, while the rates are even higher among identical twins (Schuckit 1999). In addition, research shows that children of alcoholics develop expectations about the effects of alcohol by observing their parents' drinking and may turn to alcohol as a means of alleviating other conditions (Ellis, Zucker, and Fitzgerald 1997). As with other behavioral conditions, the gene-environment interaction increases children of alcoholics' risks of developing alcohol abuse or dependence. This higher predisposition to misuse alcohol may affect labor market outcomes through its negative effects on human capital formation and employment. Yamada, Kendrix, and Yamada (1996), Chatterji and DeSimone (2005), and Koch and McGeary (2005) find that drinking in high school significantly reduces the probability of high school graduation. Williams, Powell, and Wechsler (2003) show that alcohol consumption in college has a negative effect on GPA, which works mainly through a reduction in the hours spent studying. Booth and Feng (2002) and McDonald and Shields (2001) find that heavy drinking significantly increases the probability of unemployment and reduces the number of weeks worked among those employed. Other work, however, finds little role for alcohol in educational attainment (Dee and Evans 2003; Koch and Ribar 2001) or unemployment (Feng et al. 2001).

Prenatal exposure to alcohol is a second channel through which parental alcohol abuse can affect children's productivity. The exposure of fetuses to high amounts of alcohol has been shown to have devastating effects on development. Fetal alcohol syndrome (FAS) has been associated with structural abnormalities, growth deficits, and neurobehavioral anomalies. Among other problems, children with FAS face deficiencies related to activity, attention, learning, memory, language, motor, and visuospatial abilities (see Mattson and Riley (1998) for a review of this literature).

The effects of parental problem-drinking on a child's health provide a third channel of transmission. Parental alcoholism has been associated with reduced family cohesion, increased odds of a single-parent household, and poor supervision of children, all of which are linked to higher behavioral and psychological problems among children (Antecol and Bedard 2007; Amuedo-Dorantes and Mach 2002; Garis 1998; Aizer 2004). Anda and colleagues (2002) find that depression is significantly related to having adverse childhood experiences, which are more frequent in a home with a parent who abuses alcohol. COAs are more likely to experience abuse or neglect that can affect their mental and physical health (Berger 2005; Markowitz and Grossman 1998). Moreover, the stress of being raised in a home with an alcoholic parent can make children vulnerable to certain health conditions, such as headache or chronic pain (Dobkin et al. 1994). The harmful effect of parental problem-drinking on children's health is underscored in the literature on children of alcoholics. Seo (1998) finds a statistically significant impact of maternal binge drinking on a child's nonnormative behavior and poor reading performance between 10-14 years of age. Jones, Miller, and Salkever (1999) provide evidence that parental alcohol misuse increases children's behavioral problems. Balsa (2006) finds that parental drinking increases children's utilization of acute health care services, such as mental health services and hospitalizations. Although fewer studies have followed these children over time, mental health problems are likely to persist in adulthood and affect 
productivity. Depression and other health conditions may decrease labor force participation, reduce attendance to work for those employed, and affect productivity and wages.

A final and more direct channel would consist in the need of an adult child to take time from school or work to take care of a parent with a drinking problem.

In sum, children of alcoholics face a number of constraints that condition their labor market outcomes in adulthood: a higher predisposition to misuse alcohol, a higher likelihood of congenital developmental problems, a stressful environment that leads to mental and possibly other health problems, and the burden of having to take care of a sick parent. The aim of this paper is to find evidence of the aggregate effect of these constraints on children's labor market success.

\section{Data and Methodology}

\section{A. The NLSY79}

The data used for this analysis is the National Longitudinal Survey of Youth 1979 (NLSY79). The NLSY79 is a nationally representative sample of 12,686 young men and women who were 14-22 years old when they were first surveyed in 1979. These individuals were interviewed annually through 1994 and are currently interviewed on a biennial basis. The NLSY79 cohort provides researchers with the opportunity to study a large sample of individuals representing American men and women born in the 1950s and 1960s and living in the United States in 1979. Labor market information includes the start and stop dates for each job held since the last interview, labor market activities (looking for work, out of the labor force) during gaps between jobs, hours worked, earnings, occupation, industry, benefits, and other specific job characteristics. In addition, the survey collects detailed information about personal and family characteristics, such as educational attainment, income and assets, health conditions that limit the ability to work, and use of alcohol and other substances.

\section{B. Definition of Variables}

\section{Dependent variables}

The analysis focuses on three indicators of labor market performance of children of problem-drinking parents at middle age: labor force participation, unemployment, and hourly wages. Rather than focusing on a single year, these measures are averaged across a period spanning six years (1996-2002 ${ }^{1}$ ) and four interviews. This implies that for individuals who were 14 years old in 1979, labor market performance is measured during the period when they were between 31 and 37 years old. For those in the other extreme (aged 22 in 1979), the analysis considers labor market outcomes while in their late thirties and early-to-mid forties (39 to 45). Working with average measures of outcomes across years has several advantages. First, it minimizes measurement error and the incidence of exogenous temporary shocks on labor market

1. Surveys were administered every two years in this period: 1996, 1998, 2000, and 2002. 
outcomes. We are interested in the permanent impact of parental problem-drinking on the labor trajectories of their offspring in adulthood, and working with averages achieves this aim more effectively than considering single years. Second, it substantially reduces problems of missing observations due to nonresponse. If an individual responded to the survey in 1996 and 1998, but did not respond in 2002, we would still have a measure of labor market outcomes. Third, averaging across years circumvents the problem of not observing a reservation wage. Because a relatively low proportion of individuals remain unemployed for six years in a row, we are more likely to observe the individual's reservation wage. Also, we are more likely to observe individuals who participate intermittently in the labor force.

Labor force participation is measured as the average number of weeks per year the respondent was out of the labor force between 1995 and 2001. Note that because of the biennial nature of the survey, the measure only considers the average number of weeks of nonparticipation corresponding to the calendar years prior to the 1996, 1998, 2000, and 2002 surveys. $^{2}$ Unemployment is defined as the average number of weeks per year the respondent was unemployed in 1995, 1997, 1999, and 2001. For the computation of hourly wages, only respondents that did not report selfemployment in the 1996-2002 surveys are considered. Hourly wages in a particular year are measured as the ratio of total wage earnings to total hours worked in that year, adjusted to 2002 values using the Bureau of Labor Statistics CPI. A measure of hourly wage is averaged across the years 1995, 1997, 1999, and 2001, and outliers showing a wage per hour below $\$ 1$ or above $\$ 300$ are dropped from the regressions (76 observations less than $\$ 1$ and eight observations more than $\$ 300$ ). To normalize the distribution, the logarithm of the average hourly wage is computed.

\section{Parental Problem-drinking}

In 1988, the NLSY respondents were asked whether they had ever had any relatives who had been alcoholics or problem drinkers at any point in their lives and, if so, to indicate their relationship to each of these relatives. A dichotomous indicator for having had a problem-drinking parent is constructed on the basis of these questions. The measure considers both biological and nonbiological parents. The data offered the possibility of constructing separate indicators for a problem-drinking mother and a problem-drinking father. However, the small number of problem-drinking mothers ( 5 percent in the female sample and 3 percent in the male sample) raised concerns about the power of the data to achieve statistically significant estimates. In addition, it was very hard to find instrumental variables that were relevant predictors of a problem-drinking mother.

\section{Demographics}

The analysis adjusts for age-nine categories ranging from 14 to 22 years old in 1979—and for race/ ethnicity_-White, Hispanic, Black, or Other. All analyses are run separately for male and female respondents.

2. While NLSY has information on the cumulative number of weeks out of the labor force since the last interview, dealing with these variables is confusing because of the different rates of responses and different interview dates. 


\section{State dummy variables}

Thirty-nine different geographic dummies are constructed to indicate the state of residency of the respondent at age 14. Due to the low number of respondents in various states, a number of observations had to be aggregated into a single category. Including state dummy variables as controls contributes to isolate the effects of a problemdrinking parent from influences at the geographic level that can affect a respondent's own propensity to drink as well as his/her human capital and labor market choices.

\section{Other data}

The relationship between a problem-drinking parent and an adult child's labor market outcomes can be mediated by a number of factors, such as family and household characteristics during childhood, investment in education, health status, drinking trajectories, and family choices, among others. While none of these measures is incorporated in the main analysis due to the inherent endogeneity, a descriptive account of such variables is presented in Table 5. Initial comparisons of these features among children of problem-drinking parents and other children can contribute to build hypotheses about the pathways linking parental problem-drinking to children's labor market outcomes.

\section{Sample and Data Description}

The sample used for this analysis excludes NLSY respondents from the military sample, who were only surveyed up to 1984 , as well as economically disadvantaged minorities of the supplemental subsample, who were not eligible for interview as of the 1991 survey. A total of 9,986 individuals were eligible for interview in 1996-2002. Of these, 9,028 responded to at least one of the four surveys administered between 1996 and 2002 (90 percent response rate). Among the remaining 9,028 observations, a total of 534 did not respond to the parental alcohol questions. The final sample has 8,494 observations, including 4,199 for males and 4,295 for females. Rates of participation in the 1996-2002 interviews do not differ across children of problem-drinking parents and other respondents.

Table 1 compares the means of the dependent variables and demographics across children of problem-drinking parents and other respondents. The statistics are shown separately for males and females. It is interesting to note that male respondents are less likely to answer the questions about parental drinking and less likely to report a problem-drinking mother or father than female respondents. Nineteen percent of male respondents report having had a problem-drinking parent, while the rate is 26 percent for females. This difference clearly indicates a reporting bias in the data. Regarding labor market outcomes, both male and female children of problem drinkers are more likely to be out of the labor force. Daughters of problem drinkers earn slightly lower hourly wages than other females. Parental problem-drinking is more prevalent in White families and less prevalent in African American families.

Table 2 describes in more detail the labor market outcomes for males and females. More than one third of male respondents and half of female respondents report at least one week out of the labor force during 1995-2001, and a few respondents stay permanently out of the labor force during the period (2.4 percent of men and 6.4 percent of women). Twenty-eight percent of both men and women experience some 


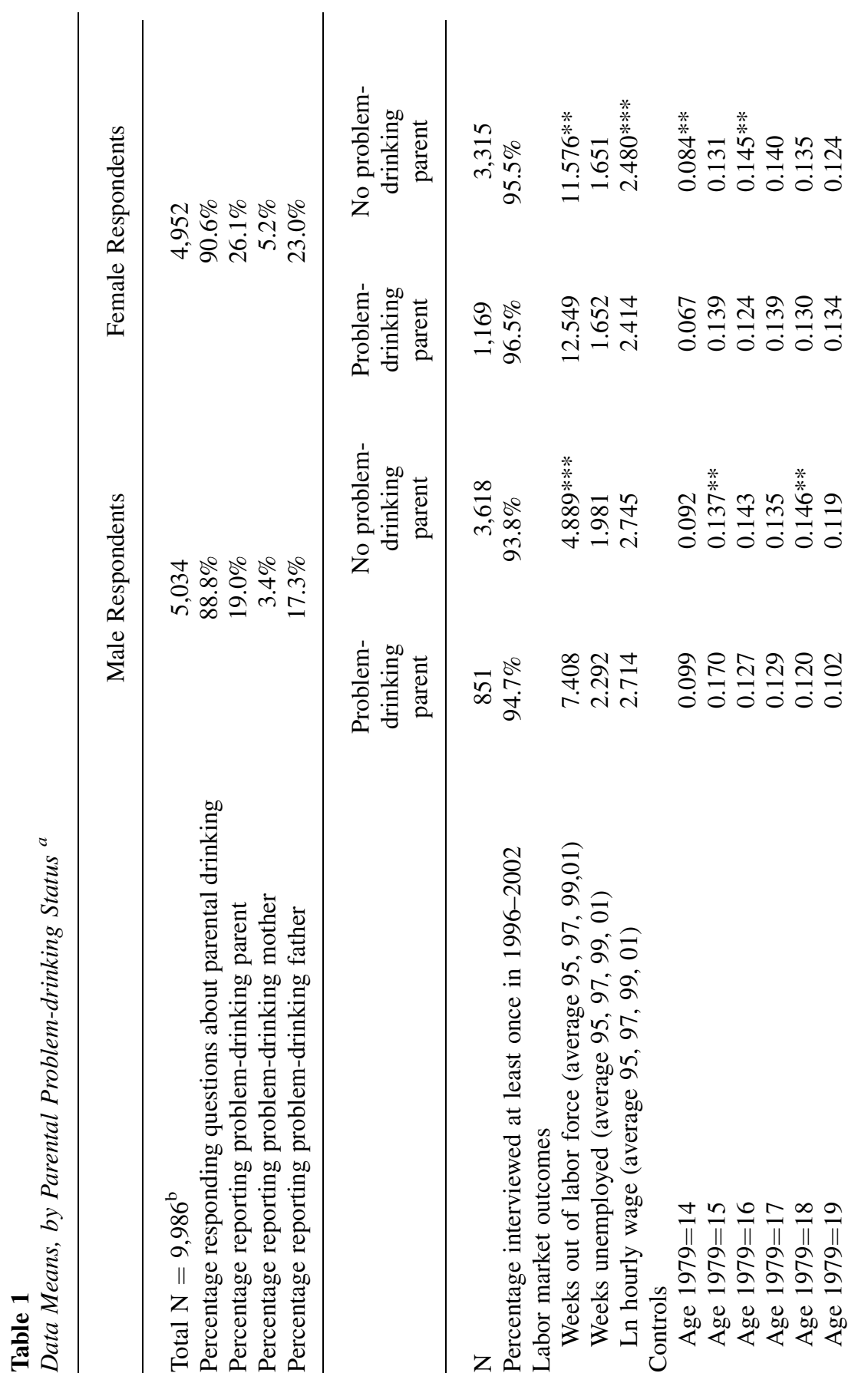




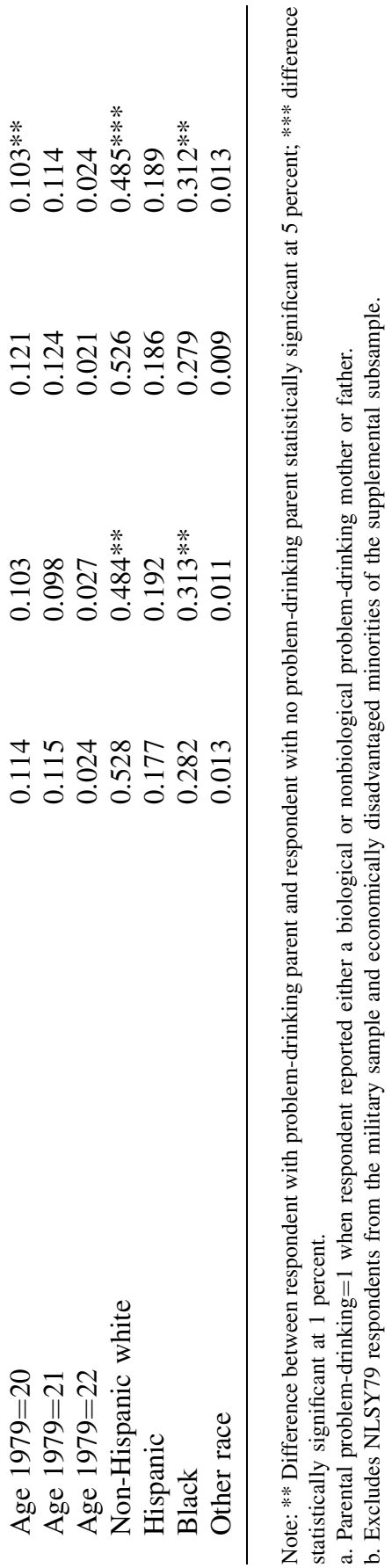


Table 2

Labor Market Outcomes for Respondents Interviewed at Least Once in 1996-2002

\begin{tabular}{|c|c|c|c|c|}
\hline & \multicolumn{2}{|c|}{ Males } & \multicolumn{2}{|c|}{ Females } \\
\hline & $\mathrm{N}$ & $\%$ & $\mathrm{~N}$ & $\%$ \\
\hline $\begin{array}{l}\mathrm{N} \text { interviewed at least once in survey years } \\
1996,1998,2000,2002 \text { with information on } \\
\text { parental alcohol problems }(\mathrm{N}=8,494)\end{array}$ & 4,199 & $100.0 \%$ & 4,295 & $100.0 \%$ \\
\hline \multicolumn{5}{|l|}{ Labor force participation } \\
\hline Permanently in the labor force & 2,559 & $60.9 \%$ & 1761 & $41.0 \%$ \\
\hline Some time but not all out of labor force & 1,499 & $35.7 \%$ & 2251 & $52.4 \%$ \\
\hline Permanently out of the labor force & 102 & $2.4 \%$ & 275 & $6.4 \%$ \\
\hline Missing labor force participation & 39 & $0.9 \%$ & 8 & $0.2 \%$ \\
\hline \multicolumn{5}{|l|}{$\begin{array}{l}\text { Working status and unemployment (among those } \\
\text { with some labor force participation) }\end{array}$} \\
\hline Permanently working while in the labor force & 2,883 & $68.7 \%$ & 2830 & $65.9 \%$ \\
\hline Some time but not all unemployed & 1,173 & $27.9 \%$ & 1178 & $27.4 \%$ \\
\hline Permanently unemployed & 2 & $0.0 \%$ & 1 & $0.0 \%$ \\
\hline Missing unemployment & 39 & $0.9 \%$ & 8 & $0.2 \%$ \\
\hline \multicolumn{5}{|l|}{ Wages } \\
\hline Wages observed & 3,835 & $91.3 \%$ & 3759 & $87.5 \%$ \\
\hline Wages not observed & 364 & $8.7 \%$ & 536 & $12.5 \%$ \\
\hline Missing because not working & 185 & $4.4 \%$ & 349 & $8.1 \%$ \\
\hline Outliers wage $\leq \$ 1$ & 34 & $0.8 \%$ & 32 & $0.7 \%$ \\
\hline Outliers wage $>\$ 300$ & 6 & $0.1 \%$ & 2 & $0.0 \%$ \\
\hline Missing because did not report wages & 139 & $3.3 \%$ & 153 & $3.6 \%$ \\
\hline
\end{tabular}

unemployment in 1995-2001. Wages are not observed for 9 percent of the male and 12 percent of the female sample.

There are two sources of sample selection in the data: attrition and failure to answer the questions about alcohol problems in the family. Table 1A in the Appendix shows the mean differences between some of the variables in the sample used for the main analysis and variables in the other two samples. Those not interviewed in 19962002 are more likely to belong to White, highly educated families and less likely to report a problem-drinking father at baseline, reducing concerns about attrition of the most severe cases. On the other hand, Hispanics and children raised in lower-income families are overrepresented among respondents who do not answer the parental alcohol use questions. These individuals are more likely to be high school dropouts and show more weeks out of the labor force. While their rate of alcohol dependence is lower than that in the final sample, there is also a higher rate of nonresponse to the DSM-IV questions. Judging from the profile of this sample, it could be possible that parental alcoholism was more severe among these individuals. If this were the case, our results would be biased toward zero by failing to include the cases more affected by parental drinking. 


\section{Methodology}

The equation of interest is of the form:

$$
Y_{i}=\alpha_{0}+\alpha_{1} A_{i}+\text { Age }_{i}^{\prime} \alpha_{2}+\text { Race }_{i}^{\prime} \alpha_{3}+\text { State }_{i}^{\prime} \alpha_{4}+\varepsilon_{i}
$$

where $Y_{i}$ is a labor market outcome and $A_{i}$ is an indicator for a problem-drinking parent. Because family, household, and many individual characteristics are endogenous, only a set of purely exogenous dummies - age, race, and fixed effects for the respondent's state of residency at age 14-are included as controls. The state dummies adjust the model for exogenous geographical influences that may shape an individual's human capital and labor market opportunities. The choice of age 14 responds to the belief that many attitudes, including the respondent's own propensity to drink, are forged during adolescence by the geographical environment. The idea is to isolate this environmental effect from parental influences due to alcohol misuse.

In addition to estimating Equation 1 with ordinary least squares, the model is estimated with alternative single equation techniques that better suit the particular outcome analyzed. In the case of count variables such as number of weeks out of the labor force and number of weeks unemployed, the model is reestimated using negative binomial regressions. When the outcome of interest is hourly wages, which involves selection due to incidental truncation, ${ }^{3}$ the model is also estimated using a Heckman two-step regression. In the first stage, I estimate the likelihood of observing the wage among all those responding to the survey. The wage regression is estimated next, adjusting for the selection implicit in the first stage. The exclusion restriction in the first stage is given by a variable constructed in 1979 that described the respondent's level of impatience when completing the interview (as reported by the interviewer).

One problem with using single-equation regression to estimate Equation 1 is that omitted variables may be biasing the results. For example, exogenous negative shocks to the family (for example, a death of a family member) may increase the likelihood that a parent becomes a problem drinker and, at the same time, deteriorate the child's mental health. Or an adverse economic period for the family could increase parental drinking and at the same time reduce the child's possibilities of graduating from high school or attending college. These mental health limitations or economic adversities could have a long-term impact upon children's productivity. It is also possible that careless personalities could lead parents to drink rather than take care of their families. Inability to control for these or other latent variables might result in spurious associations between parental drinking and children's long-term outcomes.

Instrumental variables, if relevant and valid, can address this problem by restricting the analysis to those components of the main explanatory variable (Problem-drinking Parent) that are uncorrelated with the error term in Equation 1. The instruments chosen to predict a problem-drinking parent are (1) an indicator of a problem-drinking grandfather on the father's side, (2) cigarette and beer excise taxes in the family's state of residence at the time of the respondent's birth, (3) cigarette excise taxes in the mother's state of birth in 1947 (approximately 14 years prior to the respondent's birth), and (4) a dummy variable indicating whether there were alcohol sales

3. Incidental truncation in this case is due to the fact that wages are only observed for people who work. 
controls in the father's state of birth in $1947 .{ }^{4}$ The indicator of a problem-drinking grandfather was constructed on the basis of the same questions (1988 survey) used to define the parental problem-drinking indicator. Excise taxes were obtained from the Book of States (1947-64).

Cigarette and beer taxes are commonly used instruments in this type of analysis (French and Maclean 2006; Mullahy and Sindelar 1996; Chatterji and Markowitz 2001). Some researchers have criticized these instruments because they may be confounded with attitudes at the geographic level. Such problem is minimized in this paper by including controls for the respondent's state of residency at age 14 and by using policy variables that were in place 14 or more years before at the respondent's state of residency and at the mother or father's state of birth. Thus, we are exploiting the variation on excise taxes across time and across states (for those parents who moved).

Problem-drinking by other family members, such as grandparents, aunts, or uncles, are highly predictive of parental problem-drinking and have been used successfully in other related studies as instruments (French and Maclean 2006; Mullahy and Sindelar 1996). Problem-drinking by a grandfather is a valid instrument only if it affects a child's labor market outcomes through paternal or maternal alcohol problems. It seems unlikely that this familial instrument would be correlated with contemporaneous shocks or other omitted variables that could simultaneously affect the children's human capital and the parent's drinking. It remains possible, however, that the influence of a problem-drinking grandfather on an adult grandchild works indirectly through other channels. Our analysis therefore recognizes that such an instrument can mitigate but probably not completely eliminate biases arising due to endogeneity. For this reason, some sensitivity analyses are conducted using only alcohol policy variables as instrumental variables. Unfortunately, alcohol policy variables tend to be weaker instruments when considered on their own.

Instrument relevance is tested using the $F$-test of the joint significance of the excluded instruments in a linear probability model predicting a problem-drinking parent. For each outcome of interest, overidentifying restrictions are tested using the Hansen $J$ statistic (Hansen 1982). ${ }^{5}$ I also run tests of subsets of the exclusion restrictions to ensure that each of the instruments, including State policies and the family drinking history indicator, satisfy by themselves the orthogonality requirements. The $C$-statistic or difference in Sargan test is used for this purpose (Hayashi 2000).

Endogeneity is addressed using generalized method of moments (GMM). Tests of heteroskedasticity revealed that most of the models analyzed had heteroskedasticity

\footnotetext{
4. The mentioned alcohol and cigarette policies were selected from a more extensive data set that included spirit, beer, wine, and cigarette taxes, as well as other policies such as state controls of alcohol sales. These policies were collected for several time periods and geographic locations: (a) at the family's state of residency by the time of the respondent's birth; (b) at the father's state of birth approximately 14 years prior to the respondent's birth; and (c) at the mother's state of birth approximately 14 years prior to the respondent's birth. Taxes in dollars were adjusted to 2002 values using the BLS CPI. The final set of instruments included those policies that achieved jointly the highest level of significance in the prediction of a problem-drinking parent.

5. The Hansen $J$ statistic differs from the Sargan's statistic in that it tests overidentifying restrictions under the assumption of heteroskedasticity. Note that failure to reject the hypothesis of no overidentification in any of these tests does not guarantee that the instruments satisfy the orthogonality requirements. Failure to reject could be due, for example, to low power in one or more of the instruments.
} 
of unknown form and GMM is more efficient than two stages least squares (2SLS) in such situation. The GMM estimator solves:

(2) $\bar{g}(\hat{\beta})=0$

where $\bar{g}(\hat{\beta})$ represents the $L$ sample moments corresponding to the population moments $g_{i}(\beta)=Z_{i}^{\prime} \varepsilon_{i}=Z_{i}^{\prime}\left(y_{i}-X_{i} \beta\right)$, and $Z$ denotes the set of excluded instruments satisfying $E\left(Z_{i} \varepsilon_{i}\right)=0$.

The $C$-statistic is used to test for the exogeneity of the main regressor, the indicator of a problem-drinking parent. ${ }^{6}$ In the absence of endogeneity, single-equation estimation, such as OLS, is unbiased and more efficient than instrumental variables estimation (either 2SLS or GMM). ${ }^{7}$

All models are run separately for female and male respondents. For robustness, the GMM regressions are rerun using only policy variables as instruments. In addition, bivariate probit estimation is conducted to assess the effects of parental problemdrinking on the likelihood of participating in the labor force and on the likelihood of being unemployed.

\section{Results}

\section{A. Parental Problem-drinking and Adult Children's Weeks Out of the Labor Force, Weeks Unemployed, and Wages}

Tables 3 and 4 display the core results for males and females respectively. Tables $3 \mathrm{a}$ and $4 \mathrm{a}$ describe the results of the different statistics used to test for heteroskedasticity and the first-stage statistics for the instrumental variables analysis, including relevance and validity of the instruments. Tables $3 \mathrm{~b}$ and $4 \mathrm{~b}$ show the estimation results for the OLS, negative binomial, Heckman, and GMM models. For space reasons, only the coefficients, $t$-statistics, and marginal effects (when relevant) of the parental problem-drinking indicator are reported for each outcome. The last row in each table displays the tests of exogeneity of the parental problem-drinking indicator. All models adjust for age, race, and state fixed effects at age 14 .

The instruments used to predict a problem-drinking parent are reported in Table 3a. When estimating number of weeks out of the labor force and number of weeks unemployed the set of instrumental variables includes a problem-drinking grandfather on the father's side, cigarette taxes in the family's state of residency at the time of the respondent's birth, and cigarette taxes at the mother's state of birth in $1947 .{ }^{8}$

6. The $C$-statistic differs from the Durbin Wu Hausman test in that it works under the hypothesis of heteroskedasticity.

7. Failure to reject exogeneity could also be due to lack of power of the instruments. In such case, we would not be able to say whether OLS estimates reflect causality.

8. Beer taxes at birth and at the mother's state of birth in 1947 were also significant in predicting a problemdrinking parent and had the right (negative) sign. However, cigarette taxes explained a higher fraction of the problem-drinking-parent variance, and the $F$-statistic evaluating the joint significance of instruments decreased when they were added together to the equation. Various studies have found significant relationships between the prices of cigarettes and alcohol demand, although there are mixed results about the sign of the effect (Cameron and Williams 2001, Picone et al. 2004, Markowitz and Tauras 2006). Cigarette taxes present higher cross-section variation (across states) relative to beer taxes and represent a higher fraction of the final price. These features could explain why cigarette taxes have better predictive power in the current setting. 


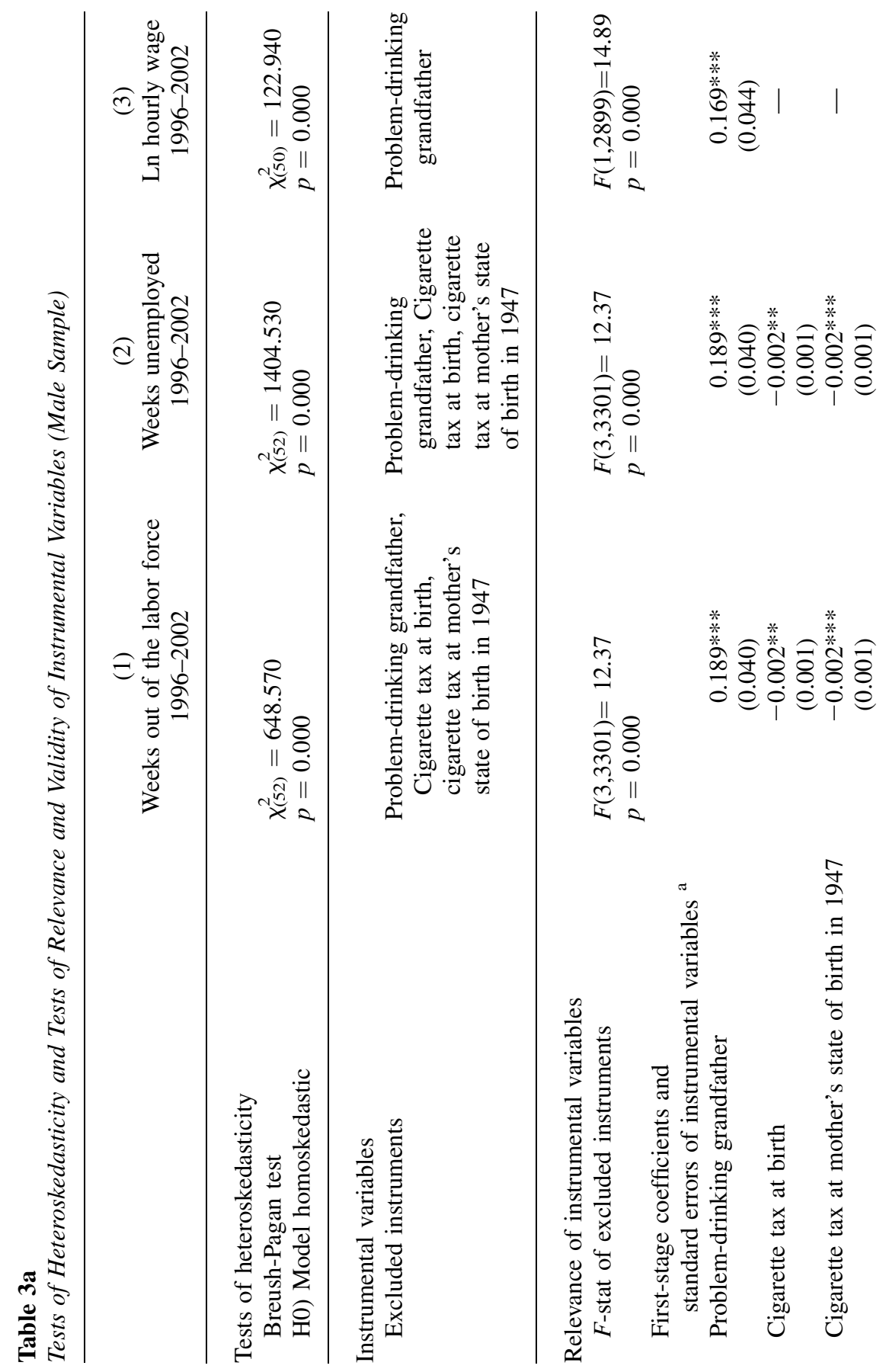




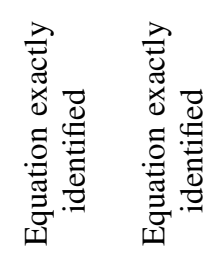

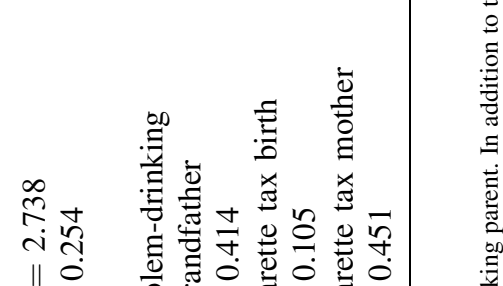

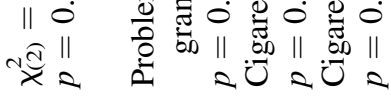

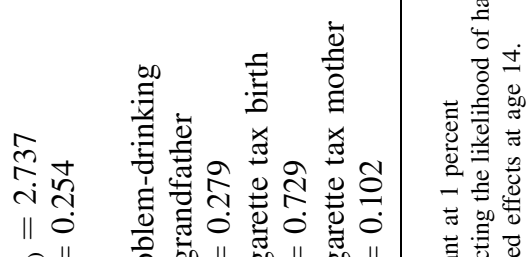

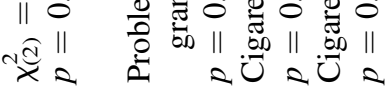




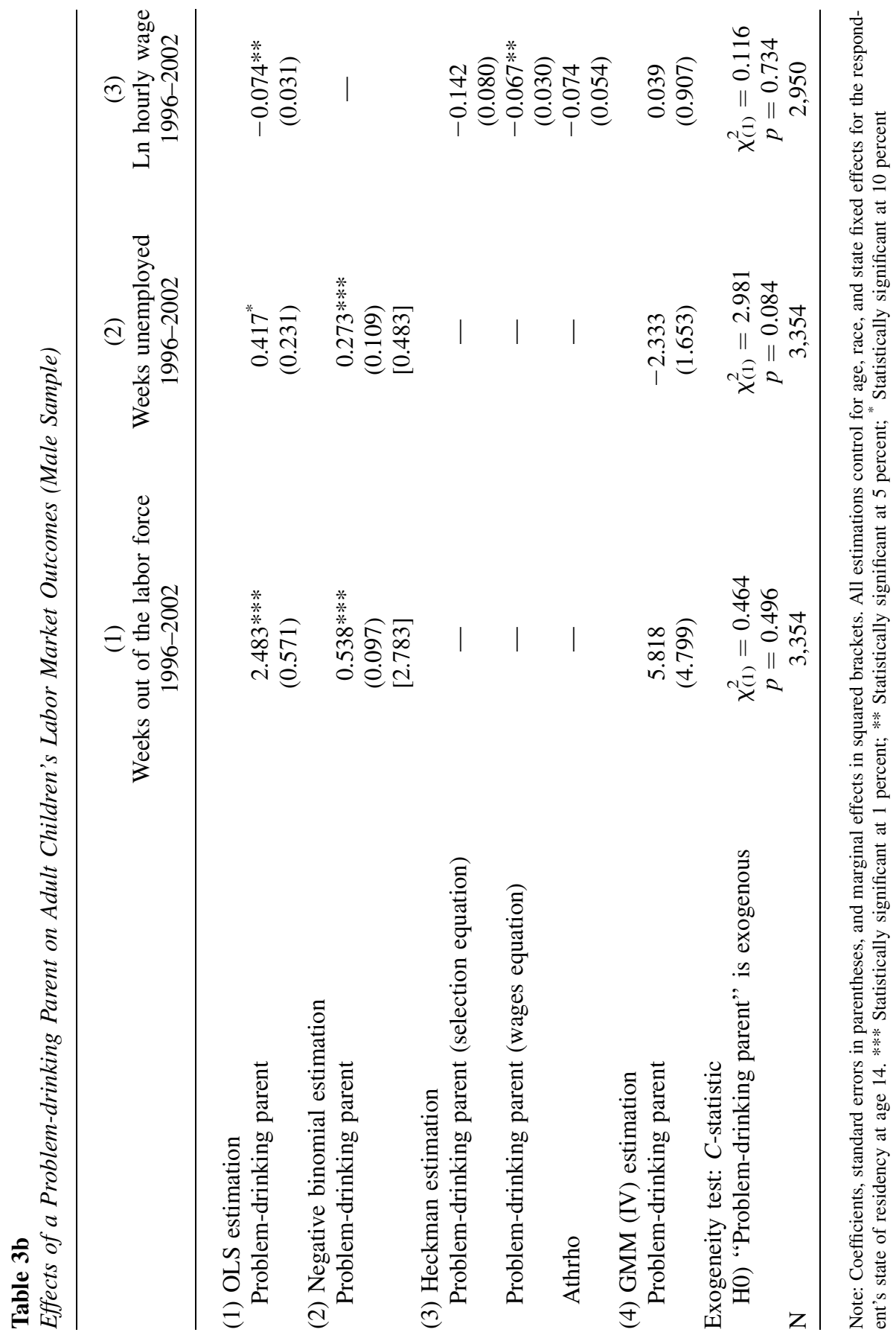


Each excluded instrument predicts a "Problem-drinking Parent" with a statistical significance of 5 percent or less. The $F$-statistics for joint significance of the instrument is above 12 . The Hansen $J$ statistic and $C$-tests of orthogonality of subsets of instruments cannot reject the null of no overidentification in the estimation of weeks out of the labor force and weeks unemployed. In particular, the $C$-statistic cannot reject the hypothesis of orthogonality between the problem-drinking-grandfather instrument and the error processes of the outcomes.

When estimating hourly wages (Table 3a, Column 3), self-employed individuals are excluded from the sample. This exclusion reduces the predictive power of the alcohol policy instruments, leaving the indicator for a problem-drinking grandfather as the sole relevant instrument. The instrument has good predictive power in the firststage (the $F$-statistic is 14.9 ), but its validity cannot be determined statistically because the model is exactly identified.

Single equation results in Table 3a suggest that having a problem-drinking parent is associated with longer periods out of the labor force, lengthier unemployment, and lower hourly wages. According to OLS and negative binomial estimates, having a problem-drinking parent increases a male respondent's time out of the labor force by around two and a half weeks (from an average of five weeks to an average of seven and a half weeks) and increases the number of weeks of unemployment in half a week per year (from a baseline of approximately two weeks for those without a problem-drinking parent). OLS and Heckman estimates also show that hourly wages of male children of problem drinkers are 7 percent below other respondents' wages.

While single equation estimates are suggestive that parental problem-drinking may have some negative effects on adult children's labor market outcomes, no conclusions about causality can be derived from those results. Unfortunately, the GMM estimation, which was expected to shed light on the causality of the detected relationships, is not informative enough. None of the GMM estimates of the effect of a problemdrinking parent achieves statistical significance, and exogeneity of the main explanatory variable cannot be rejected at 5 percent significance for any of the analyzed outcomes. This failure to find statistically significant effects is most likely due to a lack of precision in the estimation, as reflected by the large standard errors of the GMM estimates.

Table 4a shows the first-stage test-statistics for females. As with male respondents, all models are heteroskedastic, instruments are relevant (the $F$-statistic is higher than 18 ), and satisfy the exclusion restrictions at 5 percent significance, even when considering subsets of them. The instrumental variables used in the estimation of females' labor market outcomes differ from those used with men. This was not unexpected given the difference in the prevalence of parental problem-drinking reported by males and females. The instruments used in the case of females are: a problem-drinking grandfather, beer excise taxes in the family's state of residency at the time of the respondent's birth, and state controls of alcohol sales at the father's state of birth in $1947 .{ }^{9}$

9. In this case, cigarette taxes were also significant in explaining the likelihood of a problem-drinking parent, but less so than beer taxes. It is hard to make comparisons between the instruments in the female and male sample. Differences in the likelihood of reporting a problem-drinking parent across genders result in a bigger pool of problem-drinking parents for female respondents than for male respondents. 


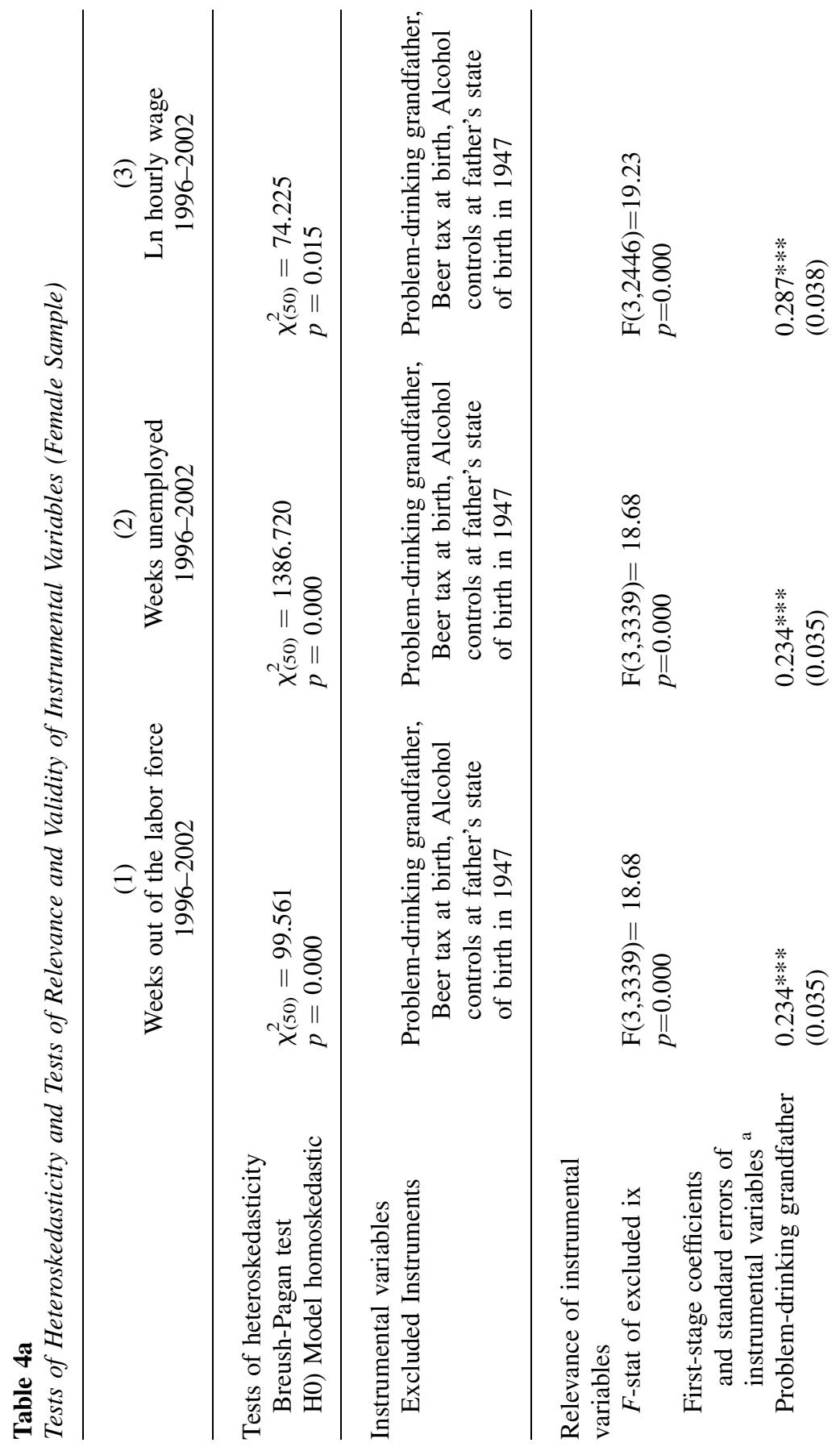




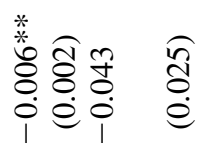

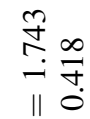

㐫

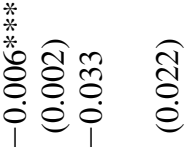

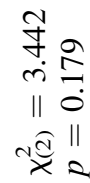

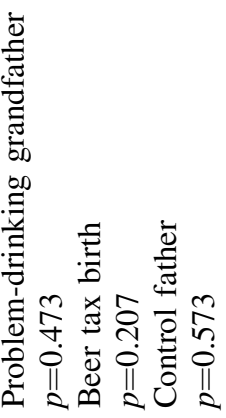

㝕
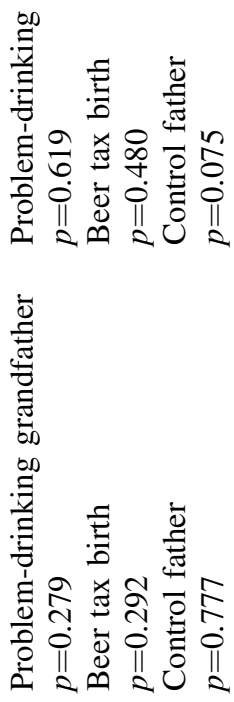

항형영

윤?

वर्व्र :

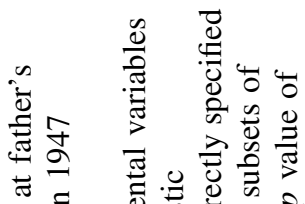

토

흥

些

里

ปั

की

옿

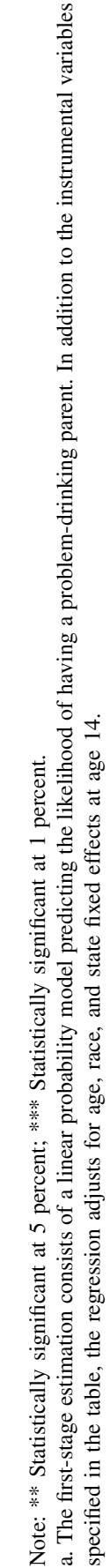




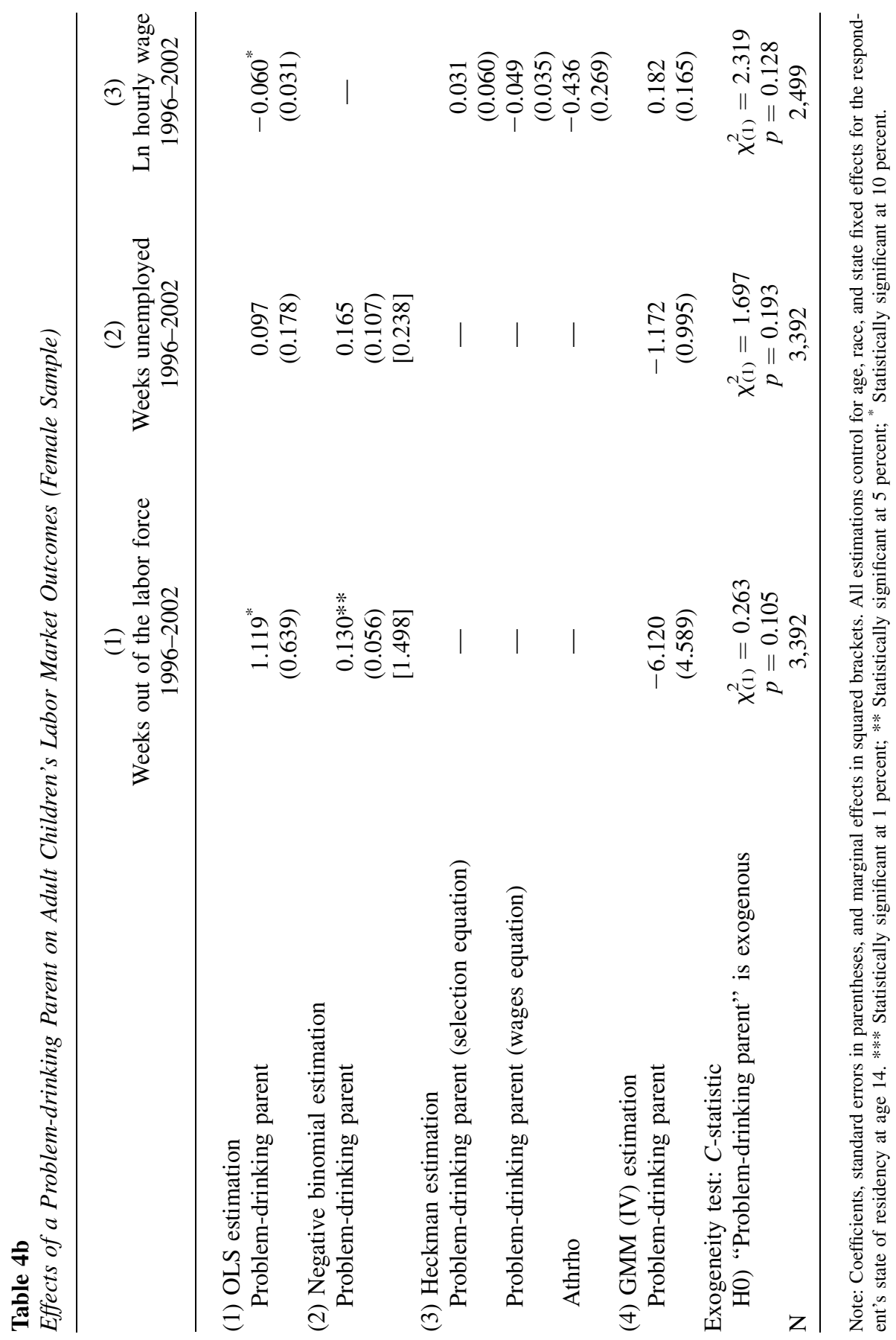


Table $4 \mathrm{~b}$ shows the effects of a problem-drinking parent on women's labor outcomes. Single equation regression reveals a statistically significant and positive association between a problem-drinking parent and women's number of weeks out of the labor force. The marginal effect is smaller than that identified for men: it stands between 1.1 and 1.5 weeks per year. No statistically significant and robust effects are identified in the estimation of weeks of unemployment or wages. As before, the exogeneity of the parental problem-drinking variable cannot be rejected in any of the models and the GMM estimates are statistically insignificant. In particular, both the estimates and the standard errors in the GMM estimation are large relative to the single equation ones, raising again concerns about the ability of the instruments to estimate the effects of interest with precision.

In sum, while the single equation estimates are indicative of detrimental effects of parental problem-drinking on children's labor market outcomes, the IV estimates are not precise enough to determine whether omitted variables bias has been successfully dealt with.

\section{B. Sensitivity Analysis Using only Policy Variables as Instruments}

For robustness, I repeat the instrumental variables estimation using only policy variables as instruments. For males, the instruments used are cigarette taxes at birth and cigarette taxes at the mother's state of birth in 1947. These variables have an $F$-statistic of joint significance of 7.4 , a value below the rule of thumb of ten generally accepted for satisfactory IV estimation, but still reasonable to check for robustness. This set of instrumental variables satisfies also the exclusion restrictions. The results obtained with these instruments are qualitatively similar to those described in Section IV.A, although the magnitudes of the standard errors raise even more concerns about the efficiency of the estimation. The exogeneity of the "Problem-drinking Parent" indicator cannot be rejected at 5 percent for weeks out of the labor force or weeks of unemployment. As in the main analysis, the GMM estimators of the effect of a problem-drinking parent do not achieve statistical significance. ${ }^{10}$ In the case of hourly wages, the alcohol policy instruments were too weak to run an alternative GMM estimation (the $F$-statistic for joint significance is barely above three).

For females, only one variable serves as relevant instrument: beer excise taxes at birth. The $F$-statistic for such an instrument in the prediction of a problem-drinking parent ranges between seven and eight, depending on the outcome. Exogeneity of the parental problem-drinking indicator cannot be rejected at 5 percent significance for any of the labor market measures analyzed but is rejected at 10 percent significance for weeks out of the labor force. GMM estimates are again statistically insignificant. ${ }^{11}$

\section{Bivariate Probit Analysis}

Rather than analyzing the number of weeks out of the labor force or unemployed, I run bivariate probit models that estimate simultaneously the probability of having a

10. For males, GMM estimates of the effect of parental problem-drinking (and standard errors) when using only policy variables as instruments are: -2.021 (8.606) for weeks out of the labor force and -4.768 (3.618) for weeks unemployed. Standard errors are twice as big as the GMM standard errors in the core results. 11. When using beer tax as the only instrument, GMM point estimates (and standard errors) of the effect of parental problem-drinking on women's number of weeks out of the labor force and unemployment are, respectively: -20.215 (14.399) and 1.148 (3.579). 
problem-drinking parent and the probability of being out of the labor force (or unemployed). Each model estimates the correlation between the error terms in the first and second regression. To identify one equation from the other, I use the same set of instruments as in the main analysis.

Results from this estimation are displayed in Tables 5 and 6. For men (Table 5), both probit and bivariate probit estimates show a positive and statistically significant effect of having a problem-drinking parent on the likelihood of being out of the labor force. The correlation term (rho) is different from zero at a statistical significance of 10 percent. Moreover, the sign of the bias is as expected; marginal effects are smaller in the bivariate probit estimation. A problem-drinking parent increases the likelihood that a son does not participate in the labor force by six percentage points in the bivariate probit estimation, compared to nine percentage points in the probit model. In the case of unemployment, the probit coefficient for a problem-drinking parent is positive and statistically significant but neither rho nor the bivariate probit coefficient is statistically significant. For women (Table 6), there is a positive and statistically significant association between parental drinking and failure to participate in the labor force when using single equation regression, but no statistically significant effects of interest are found in the bivariate probit estimation.

\section{Discussion and Conclusion}

Using NLSY79, this paper studies the association between parental problem-drinking and children's labor market outcomes at adulthood. Labor market outcomes are measured while the respondents are in their late 30 s to mid-40s, a stage in which return to school or early retirement are less likely to be behind labor market decisions. Results from single equation regressions are suggestive of important intergeneration costs of problem-drinking. For men, having a problem-drinking parent is associated with longer periods out of the labor force, lengthier unemployment spells, and lower wages. For women, an association is identified between parental problemdrinking and time out of the labor force. While the analysis attempts to address endogeneity, instrumental variables (GMM) estimation is not precise enough to conclude about the causality of these effects. On the other hand, results from bivariate probit estimation, a technique that addresses endogeneity but is less likely to be affected by low-powered instruments, support a negative effect of parental problem-drinking on male children's labor force participation.

Although the paper did not seek to identify concrete mechanisms of transmission of the effect of parental drinking on adult children's labor market outcomes, it is interesting to conjecture about possible channels of influence. A simple comparison of means presented in Table 7 shows that children of problem drinkers are, in effect, disadvantaged in several aspects. Families with problem-drinking parents are more likely to be nonintact and of lower socioeconomic status. Regardless of gender, children of problem drinkers have lower educational attainments: they are more likely to drop out of high school and less likely to achieve college or graduate education. They are also more likely to experience depressive symptoms at middle age and have higher odds of experiencing health conditions that limit the type or amount of work they can do. Relative to children of sober parents, children of alcoholics are more 


\section{Table 5}

Effects of parental problem-drinking on the likelihood of being out of the labor force and of being unemployed (Male sample)

(1)

Any weeks out

of the labor force

1996-2002
Any weeks unemployed 1996-2002

(1) Probit estimates

Problem-drinking parent

$0.231 * * *$

(0.057)

[0.089]

(2) Recursive bivariate probit estimates ${ }^{\mathrm{a}}$

Problem-drinking parent
$0.861 * *$

[0.055]

$-0.361^{*}$

(0.197)
$0.168 * * *$

$(0.060)$

[0.058]

$-0.168$

(0.399)

[-0.012]

0.192

(0.229)

Note: Coefficients, standard errors in parentheses, and marginal effects in squared brackets. All estimations control for age, race, and state fixed effects for the respondent's state of residency at age 14. *** Statistically significant at 1 percent; ** Statistically significant at 5 percent; ${ }^{*}$ Statistically significant at 10 percent. a. Instruments used to identify reduced form problem-drinking equation are cigarette tax at state of birth, cigarette tax at mother's state of birth in 1947 and problem-drinking grandfather. $\mathrm{Chi}^{2}$ test of joint significance of instruments $=44.29(p=0.000)$

likely to start drinking by age 15 and more likely to be alcohol dependent ten and 15 years after the baseline interview. Most or all of these variables are endogenous and no causality can be inferred from the comparisons. However, we can at least speculate that the impacts on health conditions and alcohol use trajectories mediate some of the effects of problem-drinking parents on children's labor force participation and wages. Future research needs to address in more depth these links.

There are several limitations to the analysis. In the first place, around 5 percent of the sample that completed at least one of the 1996-2001 interviews did not respond to the questions about problem-drinking in the family. An initial mean comparison showed that these respondents belong to a fraction of the population with a higher risk of having alcoholic parents. The omission of these individuals from the final sample could be biasing our estimates toward zero.

A second problem may result from reporting bias. The data shows that the thresholds that males use to define an alcohol problem are different from those used by females. This may not be important if the extent to which an individual is affected by parental alcoholism depends on his or her personal or subjective threshold. In other words, an individual may have a lower threshold when defining "parental problem-drinking" because she or he is by nature more readily affected by such a problem. However, if thresholds are objective, male underreporting of parental problemdrinking will bias the results toward zero. Another type of reporting bias may result 
Table 6

Effects of parental problem-drinking on the likelihood of being out of the labor force and of being unemployed (Female sample)

Any weeks out

of the labor force

Any weeks

1996-2002 unemployed 1996-2002

(1) Probit estimates

Problem-drinking parent

$0.157 * * *$

0.070

(0.046)

(0.048)

[0.061]

[0.023]

(2) Recursive bivariate probit estimates ${ }^{\mathrm{a}}$

Problem-drinking parent

$-0.145$

$(0.338)$

$[-0.014]$

Rho

0.158

0.268

(0.199)

$(0.250)$

Note: Coefficients, standard errors in parentheses, and marginal effects in squared brackets. All estimations control for age, race, and state fixed effects for the respondent's state of residency at age 14. *** Statistically significant at 1 percent; ** Statistically significant at 5 percent; ${ }^{*}$ Statistically significant at 10 percent. a. Instruments used to identify reduced form problem-drinking equation are beer tax at state of birth, whether there were alcohol controls at father's state of birth in 1947 and problem-drinking grandfather. $\mathrm{Chi}^{2}(3)$ test of joint significance of instruments $=61.21(p=0.000)$

from sicker people having a more distorted recall of their past family problems. Having objective quantitative information on parental drinking would probably improve the consistency of the estimates and provide better information for policy purposes. At this point, I am unaware of any data set that can provide better information than the NLSY on parental drinking and on children's long term labor market outcomes at a nationally representative level.

Third, it is possible that results are being led by problem-drinking fathers, concealing other interesting effects. Around 20 percent of respondents reported a problemdrinking father while only 4 percent admitted having a problem-drinking mother. The small number of problem-drinking mothers in the data does not provide enough power to achieve statistically significant effects. If effects worked across gender lines (fathers affecting sons and mothers affecting daughters), as some literature and preliminary analyses of the data appeared to suggest, the weaker findings for females might be due to poor power rather than to genuine effects.

Fourth, the methodology in the main analysis relies on the use of an indicator of a problem-drinking grandfather as an instrumental variable. While the instrument satisfied formally the exclusion restrictions, its exogeneity could be questionable on theoretical grounds. Thus, by using such variable, the expectation was to at least mitigate, but not necessarily eliminate biases due to endogeneity. 


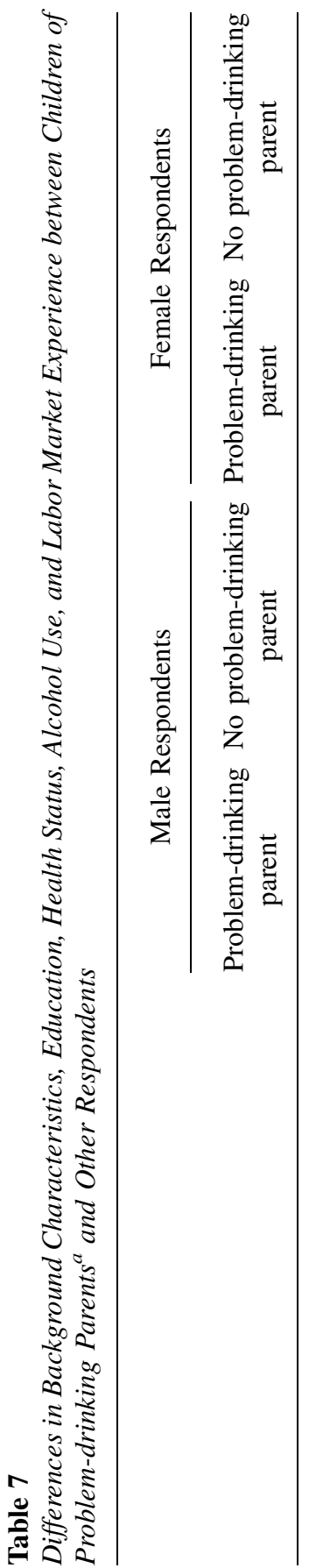

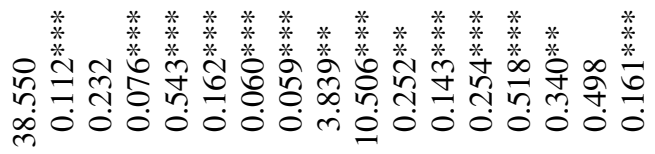

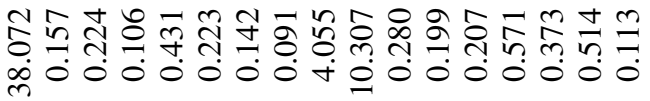

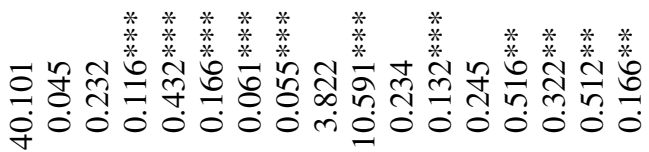

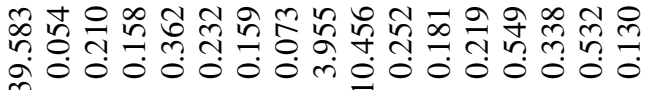

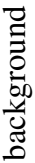

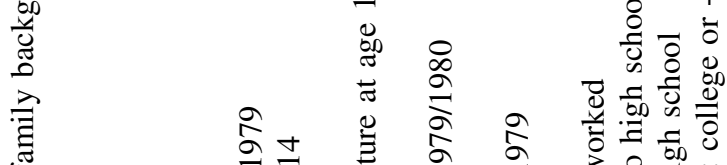

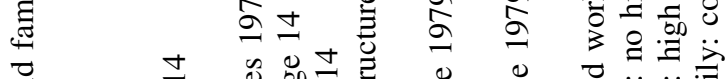

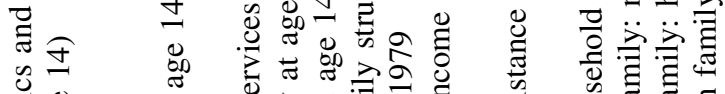

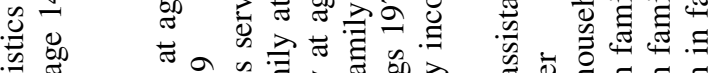
总 히 a

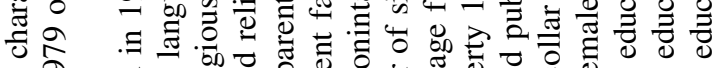

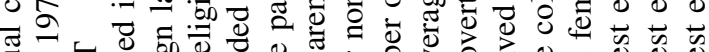

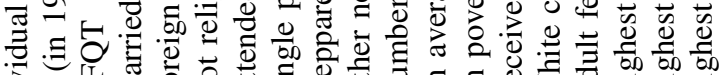

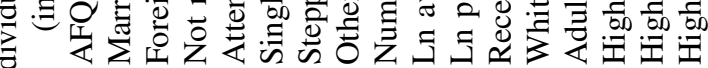
亲 


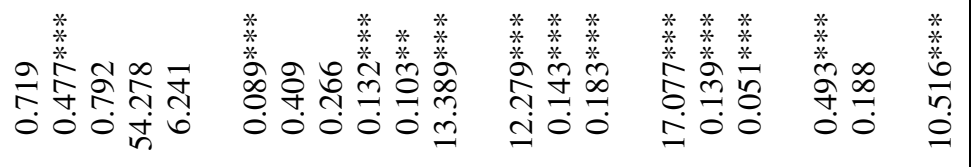

竞

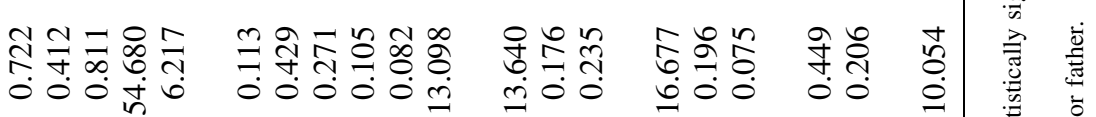

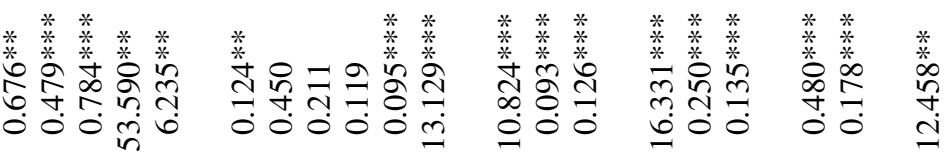

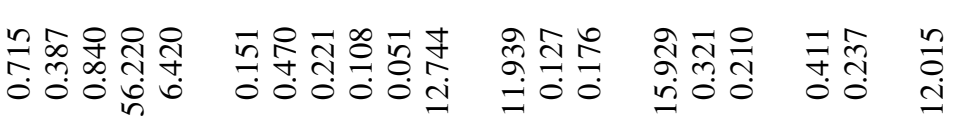

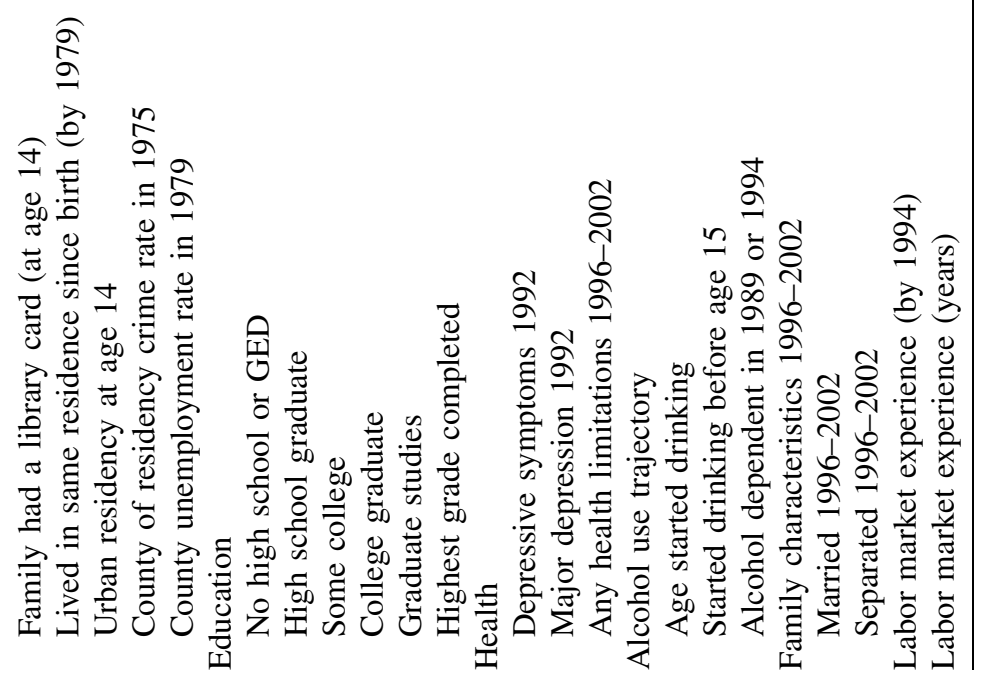


Fifth, the magnitudes of the standard errors in the GMM estimations raise concerns about the power of the instruments to identify statistically significant results. This imprecision limits our ability to say anything definitive about causality. Omitted variable bias could still be behind the detected associations between parental problemdrinking and children's labor market outcomes.

The psychopathological consequences of parental drinking on adult children have received special attention in the area of psychology and family medicine. In economics, however, none of the available estimates of the consequences of alcoholism used for policy purposes (to design, finance, and evaluate interventions) account for the impact of parental drinking on children. These estimates are restricted to measuring the direct health care costs, productivity losses, and crime costs imposed upon society by the individual with a drinking problem. This paper highlights the importance of accounting, in addition, for the losses in productivity suffered by adult sons of alcoholics, which are manifested through lower labor force participation and lower wages. Furthermore, it indicates the need to research and quantify the health care costs that children of alcoholics and society as a whole have to bare due to parental alcoholism. Policy recommendations, and in particular the types of interventions designed, may change substantially if these consequences are taken into consideration. 


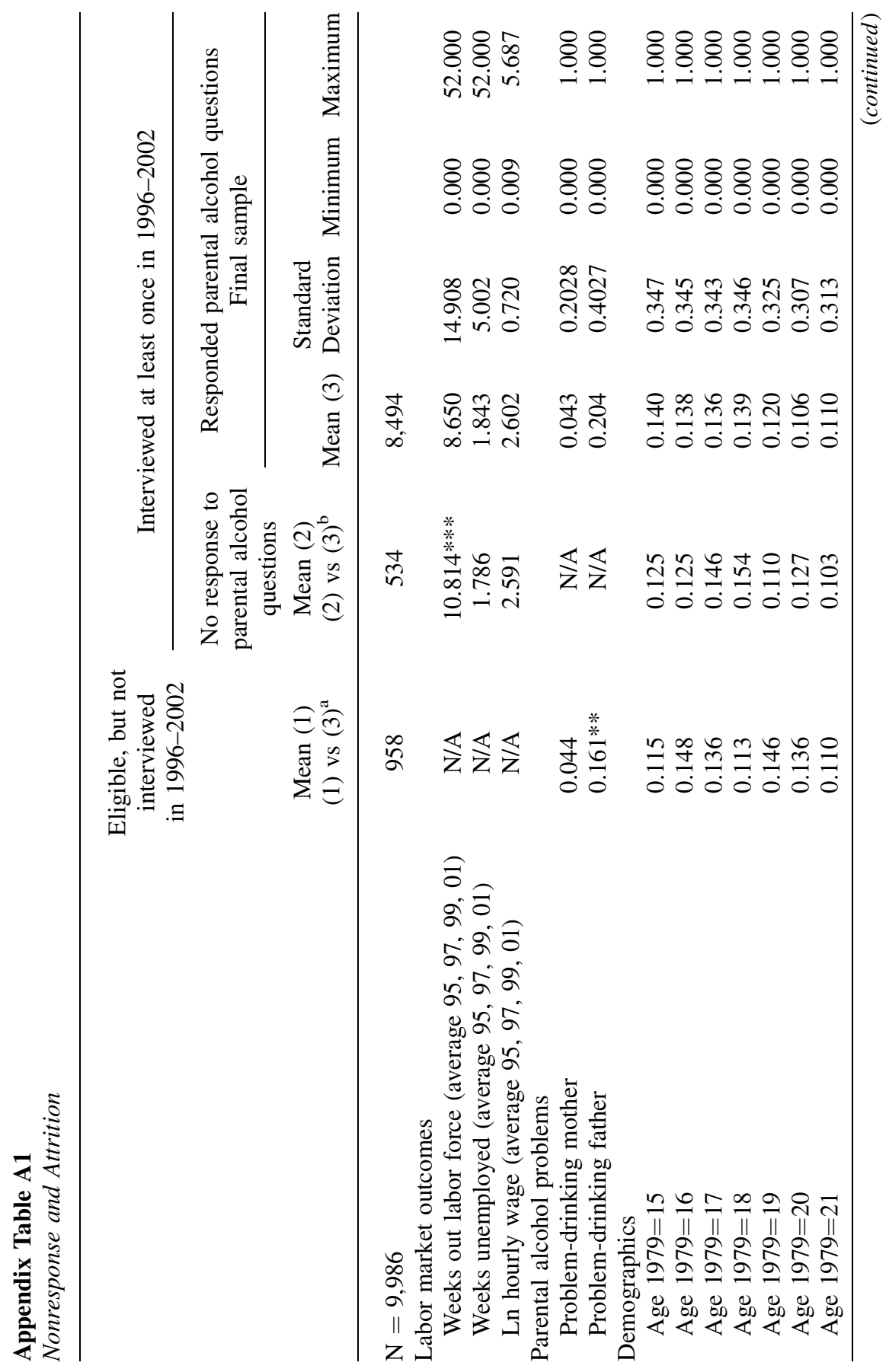




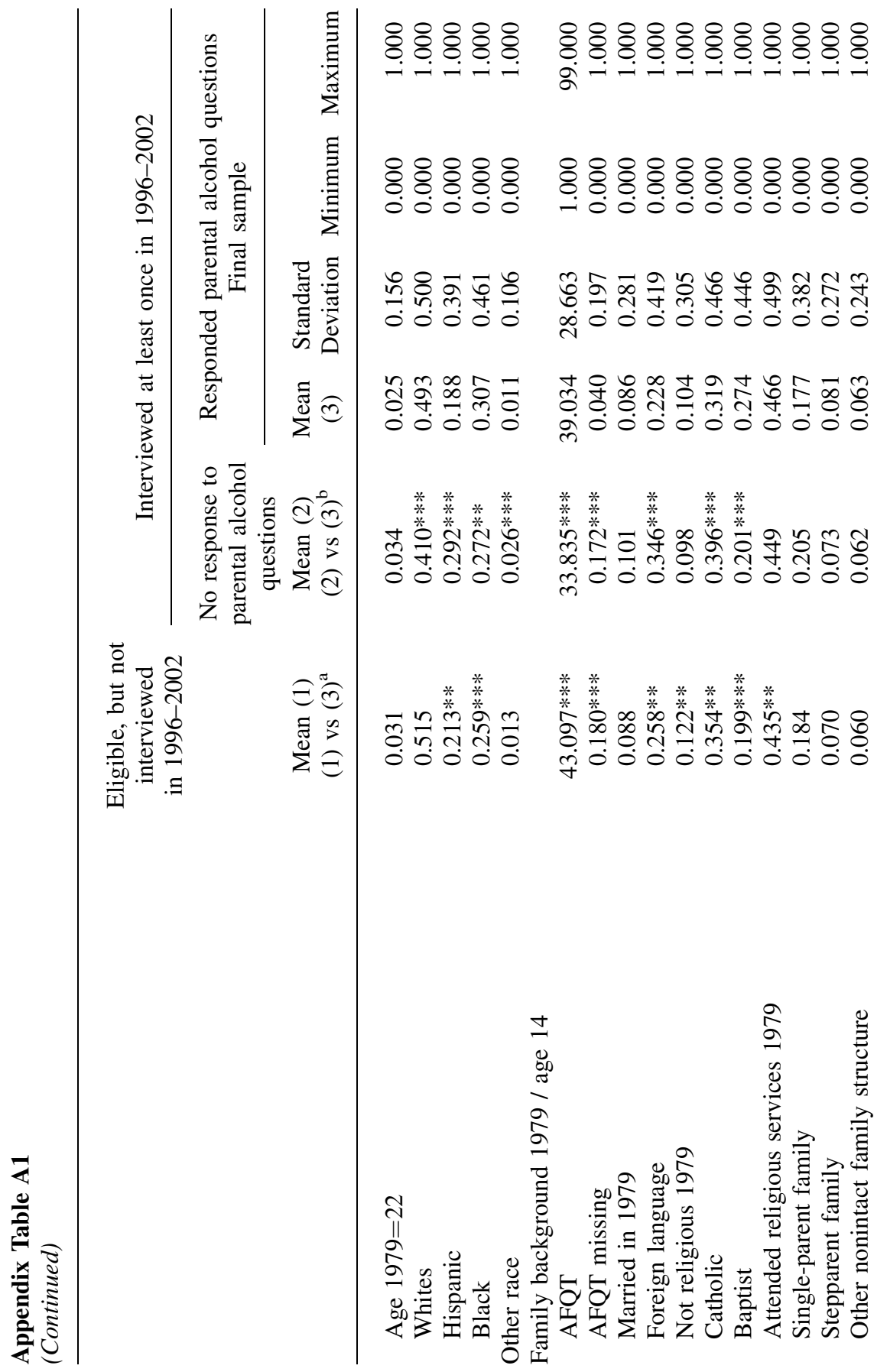




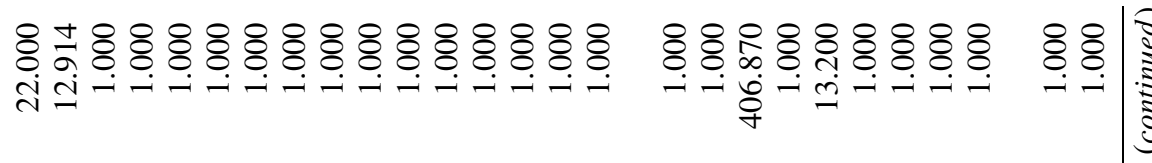

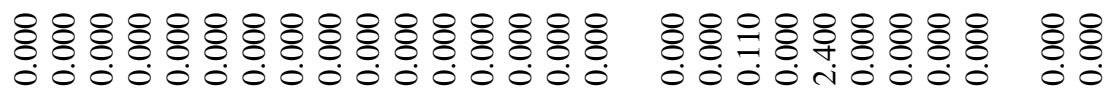

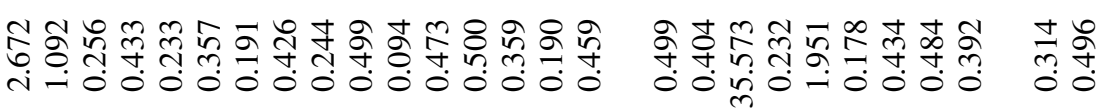

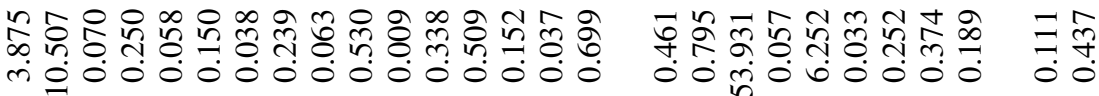

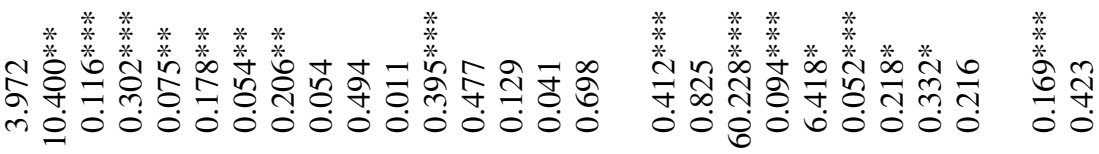

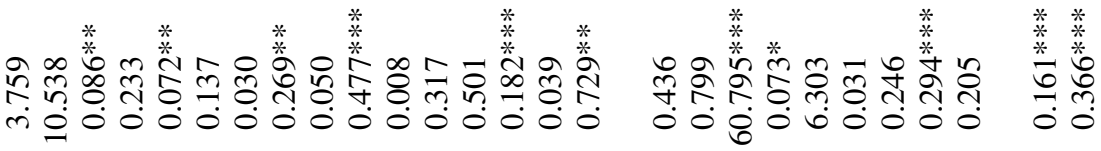

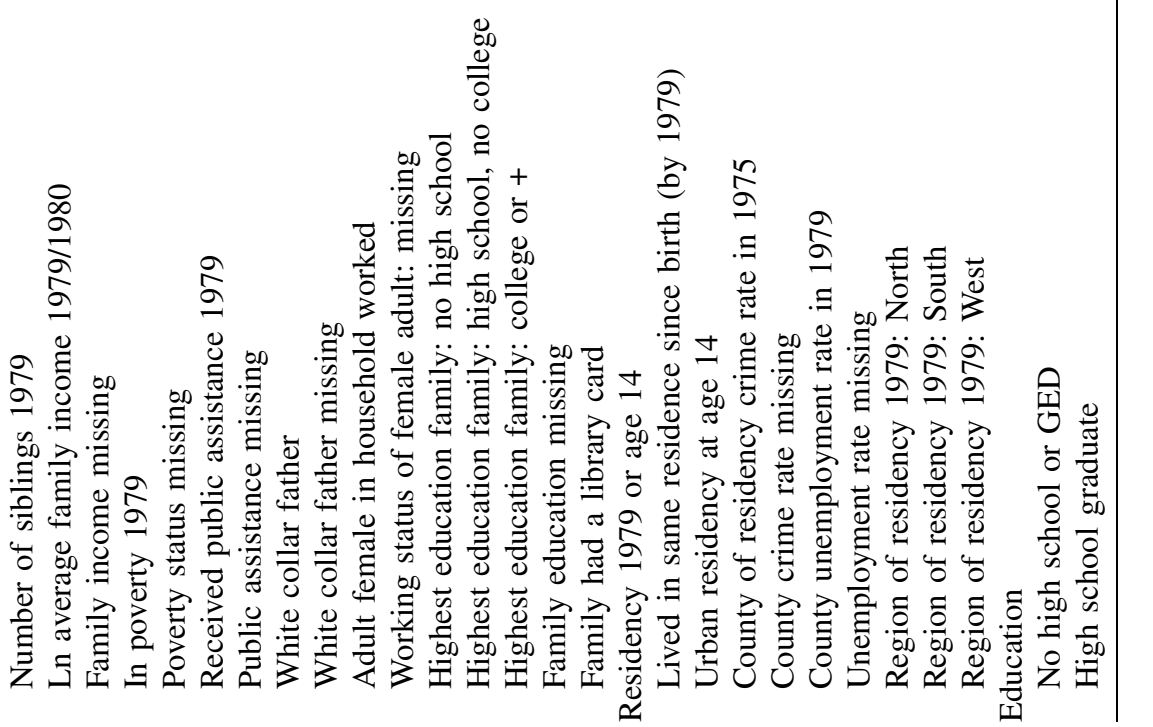




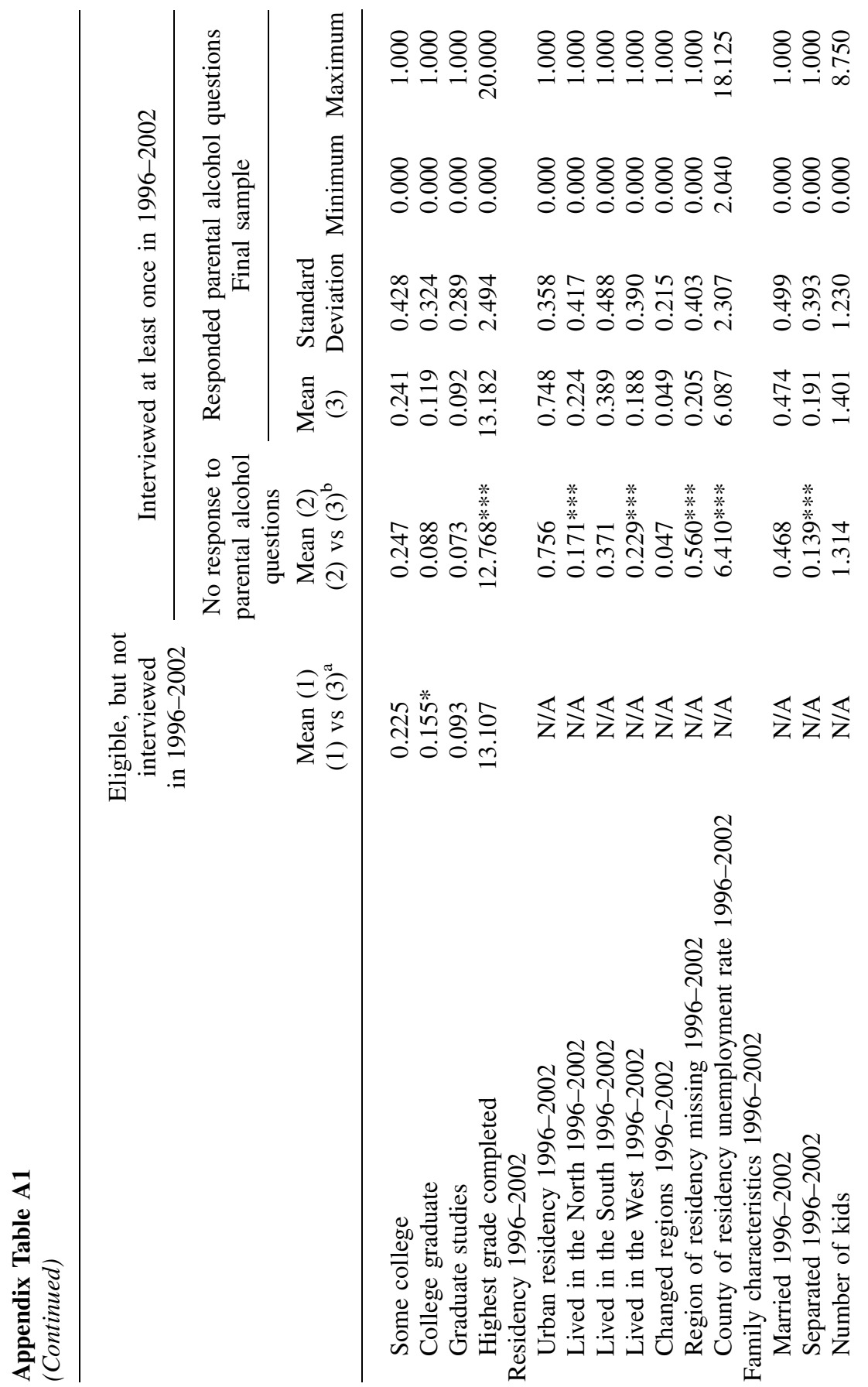




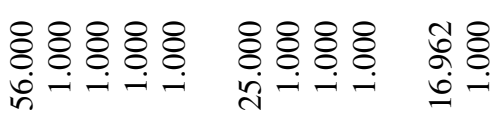

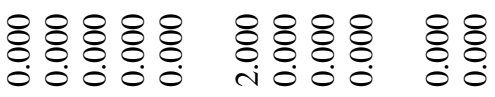

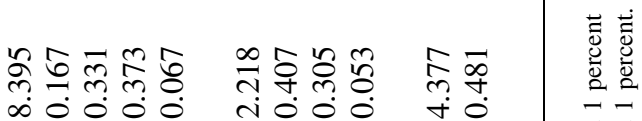

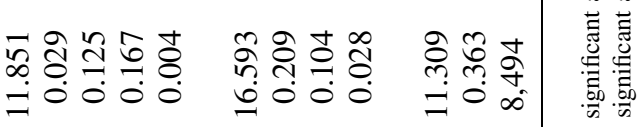

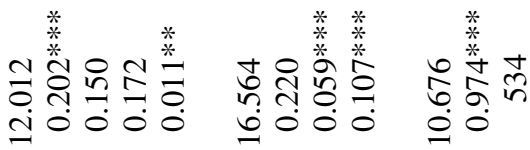

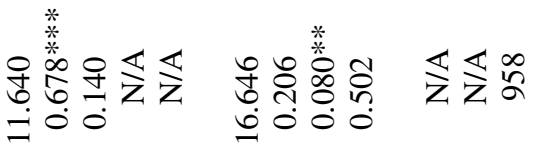
글

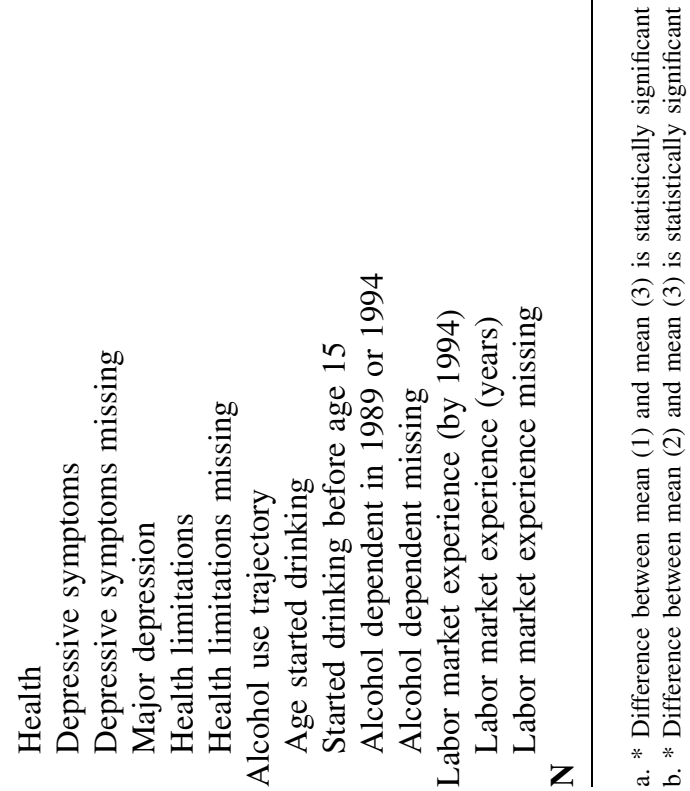




\section{References}

Aizer, Anna. 2004. "Home Alone: Supervision after School and Child Behavior." Journal of Public Economics 88(9-10):1835-48.

Amuedo-Dorantes, Catalina, and Traci Mach. 2002. "The Impact of Families on Juvenile Substance Use." Journal of Bioeconomics 4(3):269-82.

Anda, Robert, Charles Whitfield, Vincent Felitti, Daniel Chapman, Valerie Edwards, Shanta Dube, and David Williamson. 2002. "Adverse Childhood Experiences, Alcoholic Parents, and Later Risk of Alcoholism and Depression." Psychiatric Services 53(8):1001-09.

Antecol, Heather, and Kelly Bedard. 2007. "Does Single Parenthood Increase the Probability of Teenage Promiscuity, Substance Use and Crime?" Journal of Population Economics 20(1):55-71.

Balsa, Ana. 2006. "The Impact of Parental Drinking on Children's Utilization of Health Care Services." Coral Gables: University of Miami. Unpublished.

Berger, Lawrence. 2005. "Income, Family Characteristics, and Physical Violence toward Children." Child Abuse and Neglect 29(2):107-33.

The Book of States. 1947-64. Lexington, KY.: Council of the State Governments.

Booth, Brenda, and Weiwei Feng. 2002. "The Impact of Drinking and Drinking Consequences on Short-term Employment Outcomes in at-Risk Drinkers in Six Southern States." The Journal of Behavioral Health Services and Research 29(2):157-66.

Cameron, Lisa, and Jenny Williams. 2001. "Cannabis, Alcohol and Cigarettes: Substitutes or Complements?" Economic Record 77(236):19-34

Chatterji, Pinka, and Sara Markowitz. 2001. "The Impact of Maternal Alcohol and Illicit Drug Use on Children's Behavior Problems: Evidence from the Children of the National Longitudinal Survey of Youth." Journal of Health Economics 20(5):703-31.

Chatterji, Pinka, and Jeff DeSimone. 2005. "Adolescent Drinking and High School Dropout." NBER Working Paper No. W11337. Available at SSRN: http://ssrn.com/abstract=723306

Connell, Arin, and Sherryl Goodman. 2002. "The Association between Psychopathology in Fathers Versus Mothers and Children's Internalizing and Externalizing Behavior Problems: A Meta-Analysis." Psychological Bulletin 128(5):746-73.

Dee, Thomas, and William Evans. 2003. "Teen Drinking and Educational Attainment: Evidence from Two-Sample Instrumental Variable Estimates." Journal of Labor Economics 21(1):178-209.

Dobkin, Patricia, Richard Tremblay, Lyse Desmarais-Gervais, and Louise Depelteau. 1994. "Is Having an Alcoholic Father Hazardous for Children's Physical Health?" Addiction 89(12):1619-27.

Ellis, Deborah, Robert Zucker, and Hiram Fitzgerald. 1997. "The Role of Family Influences in Development and Risk." Alcohol Health and Research World 21(3):218-26.

Feng, Weiwei, Wei Zhou, J.S. Butler, Brenda Booth, and Michael French. 2001. "The Impact of Problem-drinking on Employment," Health Economics 10(6):509-21.

French, Michael, and Johanna Maclean. 2006. "Underage Alcohol Use, Delinquency, and Criminal Activity." Health Economics 15(12):1261-81.

Garis, Dalton. 1998. "Poverty, Single-Parent Households, and Youth at-Risk Behavior: An Empirical Study." Journal of Economic Issues 32(4):1079-06.

Hansen, Lars. 1982. "Large Sample Properties of Generalized Method of Moments Estimators." Econometrica 50(3):1029-54.

Hayashi, Fumio. 2000. Econometrics. Princeton, N.J.: Princeton University Press. Jennison, Karen, and Kenneth Johnson. 1998. "Alcohol Dependence in Adult Children of Alcoholics: Longitudinal Evidence of Early Risk." Journal of Drug Education 28(1): 19-37. 
2001. "Parental Alcoholism as a Risk Factor for DSM-IV-Defined Alcohol Abuse and Dependence in American Women: The Protective Benefits of Dyadic Cohesion in Marital Communication." American Journal of Drug and Alcohol Abuse 27(2):349-74.

Jones, Alison, Deborah Miller, and David Salkever. 1999. "Parental Use of Alcohol and Children's Behavioural Health: A Household Production Analysis." Health Economics 8(8):661-83.

Koch, Steven, and Kerry McGeary. 2005. "The Effect of Youth Alcohol Initiation on High School Completion." Economic Inquiry 43(4):750-65.

Koch, Steven, and David Ribar. 2001. "A Siblings Analysis of the Effects of Alcohol Consumption Onset on Educational Attainment." Contemporary Economic Policy 19(2):162-74.

Markowitz, Sara, and Michael Grossman. 1998. "Alcohol Regulation and Domestic Violence towards Children." Contemporary Economic Policy 16(3):309-20.

Markowitz, Sara, and John Tauras. 2006. "Even for Teenagers, Money Does Not Grow on Trees: Teenage Substance Use and Budget Constraints.” Cambridge: NBER Working Paper 12300.

Mattson, Sarah, and Edward Riley. 1998. "A Review of the Neurobehavioral Deficits in Children with Fetal Alcohol Syndrome or Prenatal Exposure to Alcohol." Alcoholism: Clinical \& Experimental Research 22(2):1-4.

McDonald, Ziggy, and Michael Shields. 2001. "The Impact of Alcohol Consumption on Occupational Attainment in England." Economica 68(271):427-53.

McGue, Matt. 1997. "A Behavioral-Genetic Perspective on Children of Alcoholics." Alcohol Health and Research World 21(3):210-17.

Mullahy, John, and Jody Sindelar. 1996. "Employment, Unemployment, and ProblemDrinking." Journal of Health Economics 15(4):409-34.

National Institute on Alcohol Abuse and Alcoholism (NIAAA). 2000. Tenth Special Report to the U.S. Congress on Alcohol and Health. Rockville, Md.: National Institutes of Health.

Picone, Gabriel, Frank Sloan, Justin Trogdon. 2004. "The Effect of the Tobacco Settlement and Smoking Bans on Alcohol Consumption." Health Economics 13(10):1063-80.

Schuckit, Marc. 1999. "New Findings in the Genetics of Alcoholism." Journal of the American Medical Association 281(20):1875-76.

Seo, G. 1998. "The Impact of Maternal Problem-Drinking on Children's Developmental Outcomes: Focus on Parenting As Mediator." Ph.D. Dissertation. The Ohio State University. Unpublished

Williams, Jenny, Lisa Powell, and Henry Wechsler. 2003. "Does Alcohol Consumption Reduce Human Capital Accumulation? Evidence from the College Alcohol Study." Applied Economics 35(10):1227-39.

Windle, Michael. 1996. "On the Discriminative Validity of a Family History of Problemdrinking Index with a National Sample of Young Adults." Journal of Studies on Alcohol 57(4):378-86.

Yamada, Tetsuji, Michael Kendrix, and Tadashi Yamada. 1996. "The Impact of Alcohol Consumption and Marijuana Use on High School Graduation." Health Economics 5(1): 77-92. 